\title{
Remineralization potential of nano-hydroxyapatite on enamel and cementum surrounding margin of computer-aided design and computer-aided manufacturing ceramic restoration
}

This article was published in the following Dove Press journal:

International Journal of Nanomedicine

\author{
Niwut Juntavee ${ }^{1}$ \\ Apa Juntavee ${ }^{2}$ \\ Preeyarat Plongniras ${ }^{3}$ \\ 'Department of Prosthodontics, \\ Faculty of Dentistry, Khon Kaen \\ University, Khon Kaen, Thailand; \\ ${ }^{2}$ Department of Pediatric Dentistry, \\ Faculty of Dentistry, Khon Kaen \\ University, Khon Kaen, Thailand; \\ ${ }^{3}$ Division of Biomaterials and \\ Prosthodontics Research, Faculty \\ of Dentistry, Khon Kaen University, \\ Khon Kaen, Thailand
}

\begin{abstract}
Objective: This study investigates the effects of nano-hydroxyapatite (NHA) gel and Clinpro (CP) on remineralization potential of enamel and cementum at the cavosurface area of computeraided design and computer-aided manufacturing ceramic restoration.

Materials and methods: Thirty extracted human mandibular third molars were sectioned at $1 \mathrm{~mm}$ above and below the cemento-enamel junction to remove the cemento-enamel junction portions and replaced them with zirconia ceramic disks by bonding them to the crown and root portions with resin cement. The enamel and cementum with an area of $4 \times 4 \mathrm{~mm}^{2}$ surrounding the ceramic disk was demineralized with carbopol. The demineralized surfaces were treated with either NHA or CP, while 1 group was left with no treatment. Vickers microhardness of enamel and cementum were determined before demineralization, after demineralization, and after remineralization. Analysis of variance and Tukey multiple comparisons were used to determine statistically significant differences at $95 \%$ level of confidence. Scanning electron microscopy and X-ray diffraction were used to evaluate for surface alterations.

Results: The mean \pm SD of Vickers microhardness for before demineralization, after demineralization, and after remineralization for enamel and cementum were $377.37 \pm 22.99,161.95 \pm 10.54$, $161.70 \pm 5.92$ and $60.37 \pm 3.81,17.65 \pm 0.91,17.04 \pm 1.00$ for the no treatment group; $378.20 \pm 18.76$, $160.72 \pm 8.38,200.08 \pm 8.29$ and $62.58 \pm 3.37,18.38 \pm 1.33,27.99 \pm 2.68$ for the NHA groups; and $380.53 \pm 25.14,161.94 \pm 5.66,193.16 \pm 7.54$ and $62.78 \pm 4.75,19.07 \pm 1.30,24.46 \pm 2.02$ for the CP groups. Analysis of variance indicated significant increase in microhardness of demineralized enamel and cementum upon the application of either NHA or CP $(p<0.05)$. Post hoc multiple comparisons indicated significantly higher remineralization capability of NHA for both enamel and cementum than $\mathrm{CP}(p<0.05)$, as evidenced by scanning electron microscopy, indicating NHA particle deposition in the area of remineralization, and crystallinity accumulation, as indicated by X-ray diffraction.
\end{abstract}

Conclusion: NHA gel and CP were capable of remineralization of the enamel and cementum. NHA was more capable in the remineralization process than CP. NHA was extremely capable in the remineralization process for enamel and cementum surrounding the margin of the computeraided design and computer-aided manufacturing ceramic.

Keywords: biomimetics, CAD-CAM, cavosurface margin, root caries, zirconia

\section{Introduction}

Aesthetic dentistry is considerably increasing in importance, leading ceramic to be a material of preferred choice in restorative dentistry. The technological advancements 
in the computer-aided designed and computer-aided manufacturing (CAD-CAM) in dentistry have been researched by clinicians and researchers for developing new ceramic materials which can render high-quality and reliable restorations along with good prognosis. Several types of ceramic materials have been developed to meet both the patients' and dentists' demands for highly aesthetic and natural appealing restorations. Several ceramic-based materials have been recently introduced for the CAD_CAM technology including resin nano-ceramic, hybrid ceramic, lithium disilicate glass ceramic, yttria-stabilized tetragonal zirconia polycrystalline, monolithic zirconia, and zirconia-reinforce lithium silicate ceramic. ${ }^{1}$ These ceramic materials have been developed with improved strength to withstand the stress from the physiologic masticatory function. However, the ceramic restorative material's accuracy is still compromised in comparison to metal ceramic restoration. ${ }^{2}$ Improper marginal adaptation of dental restoration induces bacterial deposition on the plaque, which initiates periodontal disease and decay, leading to the failure of restoration. ${ }^{2}$ Underprivileged marginal fit of CADCAM restoration often causes decay around the finishing line of restoration, which is generally placed on the enamel, close to the cemento-enamel junction (CEJ). However, the finishing line is occasionally placed on the cementum, close to the CEJ, in the advanced reconstruction of the periodontal involvement dentition using fixed prosthesis. Long-term clinical success of the restoration is influenced by the restorative margin's accuracy to be adapted to the finishing line, which is placed on either the cementum or the enamel.

Dental caries is a dietary carbohydrate-modified bacterial infectious disease and is one of the most common bacterial infections in humans. It is a threat to oral and systemic health, and creates a heavy financial burden worldwide. ${ }^{3}$ The basic mechanism of dental caries is demineralization through the attack by acids generated by bacteria in dental plaque biofilms. Acidogenic bacterial growth and biofilm formation with exposure to fermentable carbohydrate are responsible for caries development. ${ }^{4}$ In the USA, 166 million dental restorations were performed annually, with an increasing number of them using ceramic for reconstruction. ${ }^{3}$ The ceramic restorations are bonded to the teeth using resin adhesive, which tends to accumulate biofilms more than other restorative procedures. ${ }^{5}$ The plaque adjacent to the restoration margins may facilitate the development of secondary caries and compromise the restoration longevity. Indeed, secondary caries around the restorative margin has been considered to be a primary reason for failure of the fixed prosthodontics, thus limiting the longevity of restorations. ${ }^{6}$ It was reported that $18 \%-22 \%$ of the fixed prostheses' abutments was affected by dental caries, leading to endodontic treatment and new prostheses replacement. ${ }^{7}$ This is due to the fact that assessment of dental caries underneath the crown margin is difficult. ${ }^{8}$ Dental caries underneath a restorative margin, either on enamel or on cementum portion, is hardly detectable by radiograph. Delayed detection of dental caries underneath a restorative margin leads to irreversible pulp involvement. ${ }^{8}$ Caries around the margin of fixed prosthesis are relatively associated with leakage through the margin of restoration, which progresses with the luting cement's dissolution. ${ }^{9}$ It is related with the incidence of root caries in the elderly people and in teeth with sclerotic dentin. ${ }^{10-12}$

The prevention of secondary caries occurrence around the restorative margin was signified by the concept of remineralization and demineralization of tooth surface. Remineralizing agents occur in various forms, such as restorative materials, fissure sealants, chewing gums, mouth rinses, and dentifrices. ${ }^{13,14}$ One of the most effective remineralizing agents in caries prevention is fluoride. Nevertheless, some concerns have been expressed about fluorosis and excess fluoride intake. ${ }^{13}$ In recent years, alterative materials for fluoride have been introduced, including casein phosphopeptideamorphous calcium phosphate and nano-hydroxyapatite (NHA), because of their anticariogenic properties. ${ }^{5,14,15}$ Hydroxyapatite has attracted much interest as a biomaterial for prosthetic applications due to its crystallographic and chemical composition of calcium and phosphate similar to that of human hard tissue. However, NHA has received much attention in the medical field for the treatment of osteoporosis as well as in the dental field for the treatment of alveolar bone destruction. ${ }^{16-18}$ NHA has been reported to provide novel prevention strategies for the treatment of dental caries, specifically in the control and management of dental plaque biofilm and remineralization of initial dental caries. ${ }^{19}$ Nanoparticles are generally considered to be of a size that is much smaller than micrometerscale, which can dramatically change the resultant properties, such as hardness, active surface area, chemical reactivity, and biological activity. ${ }^{20}$ Nanoparticles were applied in restorative dentistry in the form of remineralizing agents. ${ }^{19}$ Several remineralization materials that are based on nanotechnology approaches have been reported for the remineralization process of early carious lesions. ${ }^{21,22}$ NHA is considered as one of the most biocompatible and bioactive materials used in medicine and dentistry in the recent years. ${ }^{19,23}$ The antibacterial effect of NHA is one of the most important properties that has been shown in several studies. ${ }^{24}$ NHA at a concentration of $10 \%$ is capable of remineralization process on enamel surface. ${ }^{14,25,26}$ Some studies have reported better or comparable remineralizing 
effects for NHA toothpaste to other toothpastes containing aminofluoride and fluoride. ${ }^{27,28}$ It was reported that NHA of 10-20 nm diameter and 60-80 nm length can promote the penetration of crystals into the interprismatic space through ion transportation and presumably united to the interprismatic protein, resulting in remineralization on the superficial layer of the artificial carious lesions and possibly reversing the progression of initial caries lesions. ${ }^{29-33}$ However, there are no reported cases till date regarding the use of any NHA in gel preparation on the early therapeutic aspect in restorative dentistry. This study aims to assess the NHA effect in a gel form, a newly developed product containing $10 \%$ nanohydroxymethyl cellulose for surface remineralization of enamel and cementum around the margin of CAD-CAM ceramic restoration.

\section{Materials and methods}

This in vitro study obtained clearance from the Ethics Committee in Human Research (Reference No: HE 592239) at Khon Kaen University. The patients whose extracted teeth were used in this research provided written informed consent.

\section{Sample preparation}

Thirty extracted human mandibular third molars were selected for this study. The samples were sectioned with a precision machine (Isomet $4000^{\circledR}$, Buehler, Lake Bluff, IL, USA) at $1 \mathrm{~mm}$ above and below the CEJ, dividing it into the crown, crown-CEJ-root (CCR), and root portions (Figure 1A). The CCR portion was removed and replaced with a zirconia ceramic disk, fabricated by CAD-CAM of the same dimension and shape. The CCR portion was used as a prototype for fabrication of a ceramic disk $(2 \mathrm{~mm}$ in thickness) (Figure 1B). The partially sintered yttria-stabilized tetragonal zirconia polycrystalline blank (inCoris ${ }^{\circledR} \mathrm{TZI}$, Dentsply Sirona, York, PA, USA) was prepared in a disk shape with similar contour as the CCR portion, but was $20 \%$ wider in size to compensate for sintering shrinkage of zirconia. The zirconia ceramic disk was further sintered in the furnace (inFire ${ }^{\circledR}$ HTC speed, Densply Sirona), according to the manufacture's instruction at $1,510^{\circ} \mathrm{C}$ for 2 hours, to derive precise ceramic thickness of $1.6 \mathrm{~mm}$ with a contour that was exactly with the same as the CCR portion. The zirconia ceramic disk was bonded in between the crown and root portion of each tooth using resin cement (SuperBond C\&B, Sun Medical, Shiga, Japan) with controlled cement film thickness that needed to be 25 microns, using a digital vernier caliper (Mitutoyo, Boulevard Aurora, IL, USA) (Figure 1C). The cement was auto-polymerized, and it took the cement 10 minutes to achieve full polymerization. The sample was placed in an acrylic block (Unifast Trad, GC Corp., Tokyo, Japan) and the surface was left exposed for further experimentation (Figure 1D). A flat surface of $4 \times 4 \mathrm{~mm}^{2}$ was created on the sample's exposed surface using a polishing machine (Ecomet $3^{\circledR}$, Buehler) (Figure 1E).

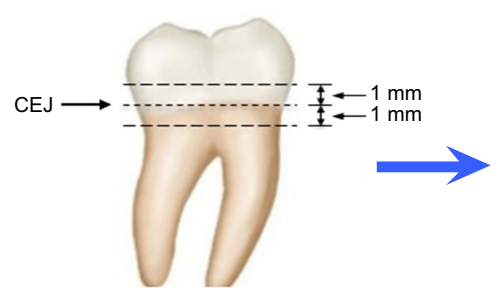

A

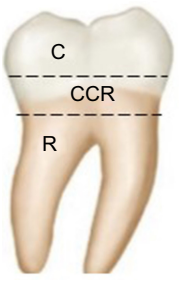

B

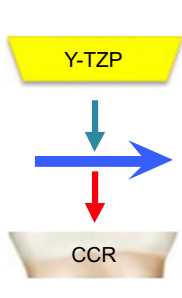

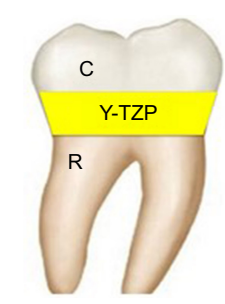

C

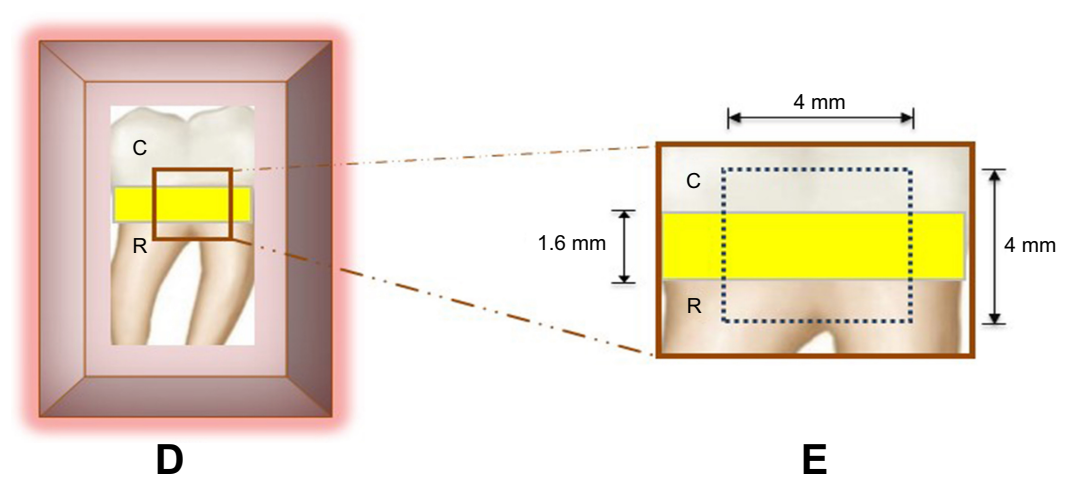

Figure I Human third molar (A) was sectioned at I mm below and above CEJ (B). The CCR portion was removed and replaced with $\mathrm{Y}$-TZP disk by bonding to the C and $R$ portion using resin cement (C), and then placed in an acrylic block (D) to create a flat surface of area $4 \times 4 \mathrm{~mm}^{2}(\mathbf{E})$.

Abbreviations: C, crown; CCR, crown-CEJ-root; CEJ, cemento-enamel junction; R, root; Y-TZP, yttria-stabilized tetragonal zirconia polycrystalline. 
The samples were washed with an air-water spray and stored in deionized water at $37^{\circ} \mathrm{C}$ for 24 hours.

\section{Formation of the induced artificial carious lesion}

The demineralized gel for artificial carious formation was prepared as a synthetic polymer gel composed of $20 \mathrm{~g} / \mathrm{L}$ of carbopol 907 (BF Goodrich Co., Cleveland, OH, USA) mixed with $0.2 \%$ polyacrylic acid and $0.1 \%$ lactic acid, adjusted $\mathrm{pH}$ to 4.4 with sodium hydroxide. ${ }^{34}$ The samples were immersed in a demineralized gel, stored in a humidified environment for 16 hours in order to induce artificial carious lesion on enamel and cementum, and then rinsed with deionized water to eliminate the demineralized gel from the sample surface.

\section{Remineralization}

The samples were randomly divided into 3 groups $(n=10)$, to be treated with either NHA gel, $0.21 \% \mathrm{w} / \mathrm{w}$ of sodium fluoride tooth cream (Clinpro; CP, 3M ESPE, St Paul, MN, USA), or to be left in deionized water to serve as a control (no treatment $[\mathrm{NT}]$ ). Each remineralizing agent was applied onto the demineralized surface of enamel and cementum, covering the $4 \times 4 \mathrm{~mm}^{2}$ area, and was left for 4 minutes before immersion in freshly prepared deionized water. The remineralized gels were applied twice a day, with a 12 hours interval in between, for a period of 30 days.

\section{Evaluation of microhardness}

The surface microhardness of the tooth was evaluated for Vickers hardness number (VHN) by indenting with
Vickers indenter, at a $100 \mathrm{~g}$ load for enamel and a $10 \mathrm{~g}$ load for cementum for 15 seconds as the dwelling time, and assessed using a microhardness tester (Digital FM-800, Future-tech, Tokyo, Japan). The microhardness on enamel and cementum was determined at a distance of 40 microns above the resin cement-enamel junction and below the resin cement-cementum junction. The microhardness was determined before the application of demineralized solution $\left(B_{D}\right)$, which served as the baseline data, after the application of demineralized solution $\left(A_{D}\right)$, and after application of the remineralized gel $\left(A_{R}\right)$. Each indentation was randomly evaluated at distances that were 100 microns apart from each other (Figure 2).

\section{Statistical analysis}

The data were statistically analyzed using SPSS statistical software version 17 (SPSS Inc., Chicago, IL, USA). Analysis of variance was used to determine the statistically significant difference in VHN upon usage of different remineralization materials at different stages of application including $B_{D}, A_{D}$, and $A_{R}$ for both enamel and cementum. Post hoc Tukey HSD multiple comparison was used to determine the difference between such factors at a $95 \%$ level of confidence.

\section{Microscopic evaluation}

Scanning electron microscope photomicrograph

Samples from each group were evaluated and compared for surface alteration of both enamel and cementum area surrounding the ceramic disk at different stages, which included $B_{D}, A_{D}$, and $A_{R}$. The sample was later coated with

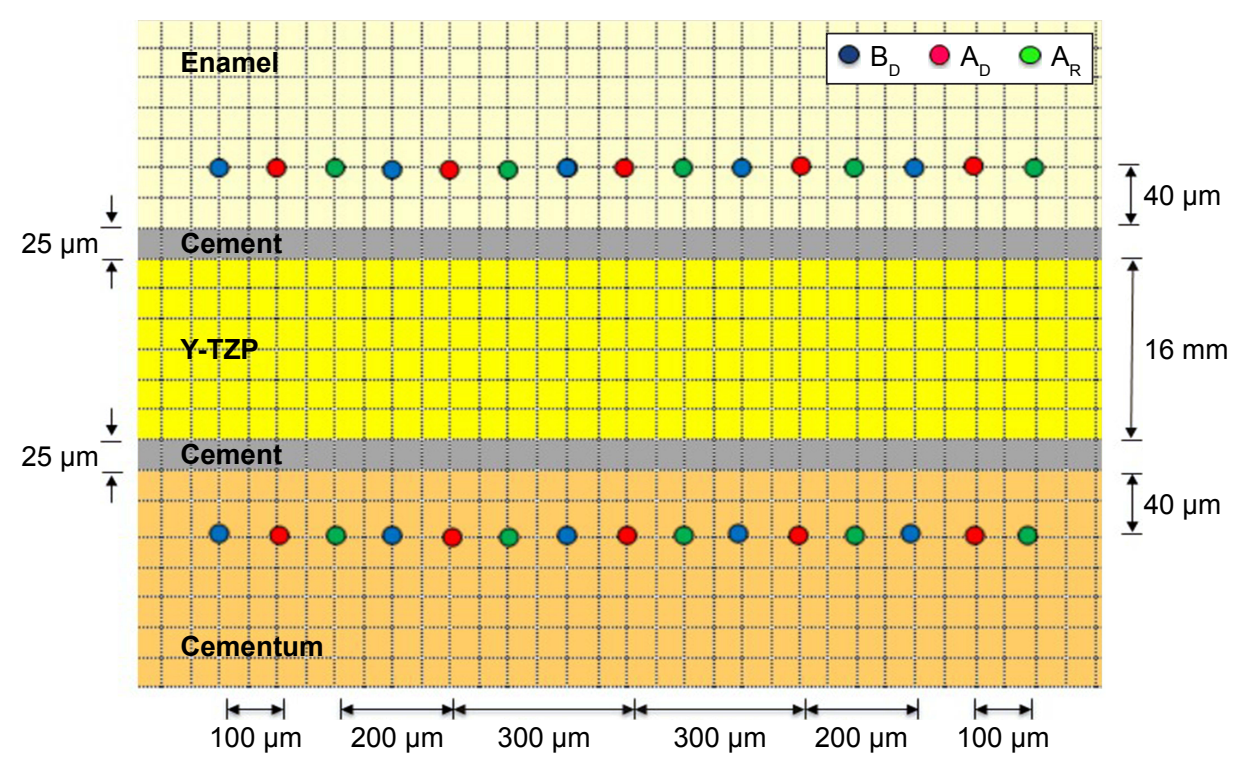

Figure 2 VHN of enamel and cementum was determined at $B_{D}, A_{D}$, and $A_{R}$ (5 locations each, 100 microns apart) at 40 microns from the enamel-resin cement junction and the cementum-resin cement junction.

Abbreviations: $A_{D}$, after demineralization; $A_{R}$, after remineralization; $B_{D}$, before demineralization; VHN, Vickers microhardness. 
gold using a sputter coating machine (Emitech-K500X, Quorum Technologies, Asford, UK) and evaluated using a scanning electron microscope (SEM, S-3000N, Hitachi, Tokyo, Japan).

\section{Determination of crystal structures}

Specimens in each group were selected to determine the crystalline structure both in the enamel and cementum using a diffractometer (PANalytical B.V., Almelo, the Netherlands). The specimens' interface surfaces were made to a fine powder and scanned with $\mathrm{Cu} \kappa \alpha$ radiations at $40 \mathrm{kV}, 30 \mathrm{~mA}$ from the $2 \theta$ degree of $20^{\circ}-60^{\circ}$. The crystalline structures were analyzed in comparison to the known standard provided by the Joint Committee on Powder Diffraction Standard, and these were determined based on the intensities peaks assessed using X'pert plus software (PANalytical B.V.) with $0.02^{\circ}$ step size every 2 seconds.

\section{Results}

The results of the remineralization on both the enamel and cementum area surrounding the margin of CAD-CAM ceramic restoration based on surface microhardness are reported in Figure 3 and Table 1. The surface microhardness values (means $\pm \mathrm{SD}$ ) for control groups $(\mathrm{NT})$ at $\mathrm{B}_{\mathrm{D}}, \mathrm{A}_{\mathrm{D}}$, and $A_{R}$ were $377.37 \pm 22.99,161.95 \pm 10.54$, and $161.70 \pm 5.92$ for enamel, and $60.37 \pm 3.81,17.65 \pm 0.91$, and $17.04 \pm 1.00$ for cementum, respectively. The surface microhardness values (means $\pm \mathrm{SD}$ ) for NHA at $\mathrm{B}_{\mathrm{D}}, \mathrm{A}_{\mathrm{D}}$, and $\mathrm{A}_{\mathrm{R}}$ were $378.20 \pm 18.76$, 160.72 \pm 8.38 , and 200.08 \pm 8.29 for enamel, and $62.58 \pm 3.37$, $18.38 \pm 1.33$, and $27.99 \pm 2.68$ for cementum, respectively. The surface microhardness values (means $\pm \mathrm{SD}$ ) for the $\mathrm{CP}$ at $B_{D}, A_{D}$, and $A_{R}$ were $380.53 \pm 25.14,161.94 \pm 5.66$, and

\section{A}

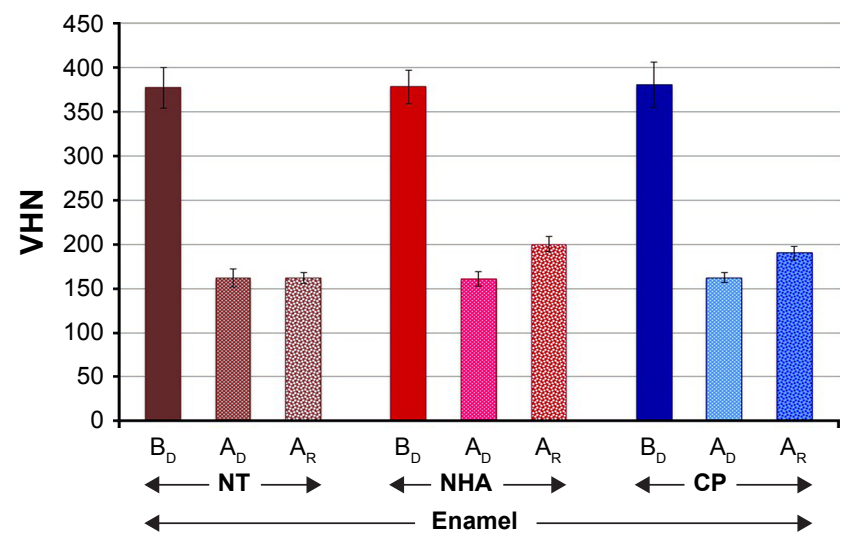

193.16 \pm 7.54 for enamel, and $62.78 \pm 4.75,19.07 \pm 1.30$, and $24.46 \pm 2.02$ for cementum, respectively.

Analysis of variance indicated significant difference in surface hardness for both the enamel and cementum area surrounding the ceramic because of different remineralizing materials and stages of material application $(p<0.05)$, but no significant difference in surface hardness upon the interaction of the material and stage of the application was found ( $p>0.05)$, as shown in Table 2. The post hoc multiple comparison indicated a significant difference in the capability of remineralization effect on the demineralized surface of either enamel or cementum area surrounding the CAD-CAM ceramic restoration for both the NHA and CP in comparison to the NT ( $p<0.05)$, as shown in Table 3 . There was a significant difference in the remineralization capability between NHA and CP on the demineralized surface of the enamel and cementum area surrounding the ceramic restoration $(p<0.05)$, as shown in Table 3 . The NHA demonstrated a higher capability of remineralization of the demineralized surface of either enamel or cementum than the $\mathrm{CP}(p<0.05)$, as shown in Table 3 and Figure $3 \mathrm{~A}$ and B.

The SEM photomicrograph demonstrated the generalized smooth surface architecture of both the enamel (Figure 4A) and cementum (Figure 4B). Generalized surface irregularities of demineralized enamel (Figure 4C) and generalized irregularities of demineralized cementum with opening tubules (Figure 4D) were noted after the demineralization process. The untreated surface of the demineralized enamel (Figure 4E) and cementum (Figure 4F) were not altered in terms of the surface architecture. The surface architecture of the enamel exhibited smoother area after the NHA (Figure 4G and $\mathrm{H}$ ) and CP (Figure 4I and J) were applied to the demineralized

B

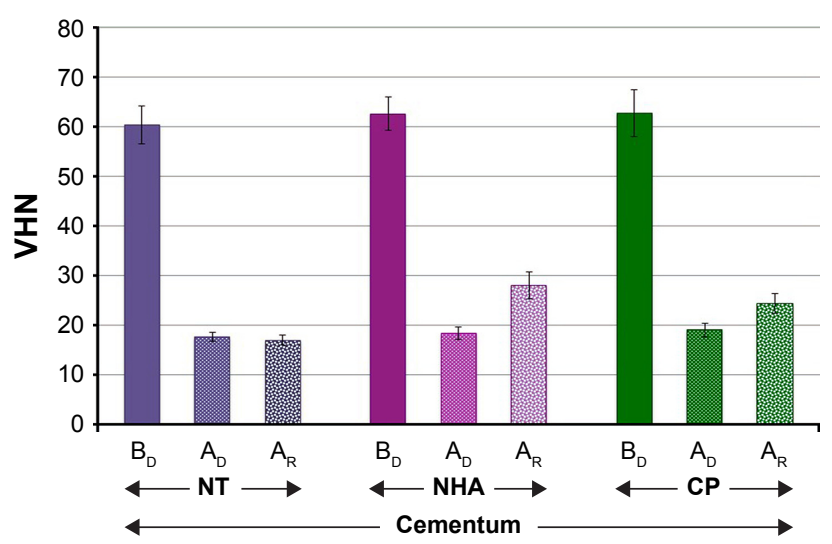

Figure 3 The mean and SD of VHN of enamel $(\mathbf{A})$ and cementum $(B) B_{D}, A_{D}$, and $A_{R}$ with NHA and CP, in comparison with NT. Abbreviations: $A_{D}$, after demineralization; $A_{R}$, after remineralization; $B_{D}$, before demineralization; $C P$, Clinpro; NHA, nano-hydroxyapatite; NT, no treatment; VHN, Vickers microhardness. 
Table I Mean, SD, and $95 \% \mathrm{Cl}$ of $\mathrm{VHN}$ of enamel and cementum $B_{D}, A_{D}$, and $A_{R}$ with NHA, CP, and NT

\begin{tabular}{|c|c|c|c|c|c|}
\hline \multirow[t]{2}{*}{ Group } & \multirow[t]{2}{*}{$\mathbf{n}$} & \multirow[t]{2}{*}{ Mean } & \multirow[t]{2}{*}{ SD } & \multicolumn{2}{|l|}{$95 \% \mathrm{Cl}$} \\
\hline & & & & $\begin{array}{l}\text { Lower } \\
\text { limit }\end{array}$ & $\begin{array}{l}\text { Upper } \\
\text { limit }\end{array}$ \\
\hline \multicolumn{6}{|l|}{ VHN of enamel } \\
\hline Enamel-NT-B $\mathrm{B}_{\mathrm{D}}$ & 10 & 377.37 & 22.99 & 360.91 & 393.82 \\
\hline Enamel-NT-A $A_{D}$ & 10 & 161.95 & 10.54 & 154.40 & 169.49 \\
\hline Enamel-NT-A $A_{R}$ & 10 & 161.70 & 5.92 & 157.45 & 165.93 \\
\hline Enamel-NHA-B ${ }_{D}$ & 10 & 378.20 & 18.76 & 364.78 & 391.62 \\
\hline Enamel-NHA-A & 10 & 160.72 & 8.38 & 154.72 & 166.72 \\
\hline Enamel-NHA-A $A_{R}$ & 10 & 200.08 & 8.29 & 194.14 & 206.01 \\
\hline Enamel-CP-B ${ }_{D}$ & 10 & 380.53 & 25.14 & 362.54 & 398.52 \\
\hline Enamel-CP-A $A_{D}$ & 10 & 161.94 & 5.66 & 157.89 & 165.99 \\
\hline Enamel-CP-A $A_{R}$ & 10 & 193.16 & 7.54 & 187.76 & 198.56 \\
\hline \multicolumn{6}{|l|}{ VHN of cementum } \\
\hline Cementum-NT- $B_{D}$ & 10 & 60.37 & 3.81 & 57.64 & 63.10 \\
\hline Cementum-NT- $A_{D}$ & 10 & 17.65 & 0.91 & 17.00 & $|8.3|$ \\
\hline Cementum-NT- $A_{R}$ & 10 & 17.04 & 1.00 & 16.32 & 17.76 \\
\hline Cementum-NHA-B ${ }_{D}$ & 10 & 62.58 & 3.37 & 60.17 & 65.00 \\
\hline Cementum-NHA-A & 10 & 18.38 & 1.33 & 17.43 & 19.34 \\
\hline Cementum-NHA-A $A_{R}$ & 10 & 27.99 & 2.68 & 26.07 & 29.91 \\
\hline Cementum-CP-B ${ }_{D}$ & 10 & 62.87 & 4.75 & 59.47 & 66.27 \\
\hline Cementum-CP-A & 10 & 19.07 & 1.30 & 18.13 & 20.01 \\
\hline Cementum-CP-A $A_{R}$ & 10 & 24.46 & 2.02 & 23.02 & 25.91 \\
\hline
\end{tabular}

Abbreviations: $A_{D}$, after demineralization; $A_{R}$, after remineralization; $B_{D}$, before demineralization; CP, Clinpro; NHA, nano-hydroxyapatite; NT, no treatment; VHN, Vickers microhardness.

enamel and cementum surface for 30 days, as compared to untreated enamel and cementum surface (Figure 4E and F). The SEM photomicrograph revealed NHA particle deposition in the tubules of cementum, as well as generalized reduction of surface irregularities (Figure 4H). On the contrary, some $\mathrm{CP}$ particles were partially precipitated in the cementum tubules with minimal irregularities of the surfaces (Figure 4J).

The X-ray diffraction (XRD) analysis indicated that the crystal structure was observed at the $2 \theta$ value of $26^{\circ}$, $29^{\circ}, 31^{\circ}, 32^{\circ}, 33^{\circ}, 34^{\circ}, 39^{\circ}, 46^{\circ}, 49^{\circ}, 51^{\circ}$, and $52^{\circ}$, which corresponded with the (002), (210), (211), (112), (300), (202), (130), (222), (213), (321), and (140) planes in both the enamel and cementum for every group. However, the major peak with highest intensity was observed at $2 \theta$ value at $32^{\circ}$ and $33^{\circ}$, which corresponded with the (211) and (300) plane for both the enamel and cementum (Figure 5A and $\mathrm{B}$ ). The peak intensity was lower in cementum than in enamel (Figure 5a and $\mathrm{b}$ ). The peak intensities decreased for $\sim 45 \%$ in enamel and $29.5 \%$ in cementum during the demineralization process (Figure $5 \mathrm{c}$ and d). The peak intensities increased during the remineralization using either NHA for $-55.3 \%$ and $18.7 \%$ in enamel and cementum (Figure $5 \mathrm{~g}$ and $\mathrm{h}$ ), or $\mathrm{CP}$ for $\sim 42.3 \%$ in enamel and $16.6 \%$ in cementum
(Figure 5i and $\mathrm{j}$ ), as compared to the untreated group for $\sim 3.9 \%$ in enamel and $1.4 \%$ in cementum (Figure $5 \mathrm{e}$ and $\mathrm{f}$ ).

\section{Discussion}

An absolutely integrated tooth-restoration junction is an important goal that is hardly achieved. Indeed, irregularities at the cavosurface junction and microgaps at the toothrestoration interfaces are always present and induce bacterial accumulation leading to tooth decay. Therefore, the remineralization concept on the restorative tooth surface junction is a preventive method in restorative dentistry. This study investigated the capabilities of NHA and CP for remineralization of the cavosurface area of enamel and cementum surrounding the CAD-CAM ceramic restoration. The study indicated that both NHA and CP were significantly capable of remineralizing to help in the recovery of the demineralized enamel and cementum in comparison to the nontreated demineralized surface $(p<0.05)$. The NHA showed significantly higher capability in remineralizing the demineralized surface of both the enamel and cementum than CP $(p<0.05)$, as evidenced by SEM, which demonstrated more particles of NHA than CP being deposited in the area of remineralization, and $\mathrm{XRD}$, which exhibited higher increasing peak intensity for enamel and cementum on NHA application in comparison to $\mathrm{CP}$. This possibly indicated that there were mechanisms of ion transportation involved in the remineralization process. ${ }^{29}$ The protein matrix comprises $\sim 1 \%$ of the organic part of a mature enamel, which possibly remains after demineralization and functions as the main scaffold for ionic conduction ${ }^{30}$ and deposition in the nanogaps of the interprismatic space, as described by other studies..$^{30,31}$ The enamel proteins situated in the interprismatic space were possibly capable of capturing the mineral solutions and allowed for penetration of minerals along the sides of these crystallites. ${ }^{29,31}$ This is also related with isomorphic and isoionic exchange processes in enamel crystals that occurred upon the diffusion of calcium and phosphate through the interprismatic spaces and converted into hydroxyapatite crystals. ${ }^{29}$ The proteins probably acted as a scaffold for ion exchange of NHA and CP. ${ }^{22,31}$ These results relate to the capabilities of NHA gel and CP to perform the remineralization process. ${ }^{13}$ The NHA has a significantly higher capability of remineralization than $\mathrm{CP}$, and this is possibly related to the NHA's nanoparticle nature, which is compatible with tooth structure. NHA is able to enhance penetration of its crystals through the interprismatic spaces of enamel, resulting in the formation of the hydroxyapatite crystals. ${ }^{29}$ The sodium fluoride and tri-calcium phosphate which make up $\sim 0.21 \%$ 
Table 2 ANOVA and multiple comparison of VHN upon using different remineralizing materials at difference stages of application for enamel and cementum $B_{D}, A_{D}$, and $A_{R}$

\begin{tabular}{|c|c|c|c|c|c|c|}
\hline \multicolumn{7}{|c|}{ ANOVA of VHN for enamel } \\
\hline \multicolumn{2}{|l|}{ Source } & SS & $d f$ & MS & $\boldsymbol{F}$ & $p$-value \\
\hline \multicolumn{2}{|l|}{ Intercept } & $\mathrm{I}, 753, \mathrm{I} 48.440$ & 1 & $\mathrm{I}, 753, \mathrm{I} 48.440$ & $16,271.160$ & 0.000 \\
\hline \multicolumn{2}{|l|}{ Material } & 983.015 & 2 & 491.507 & 4.562 & 0.020 \\
\hline \multicolumn{2}{|l|}{ Error } & $2,909.135$ & 27 & 107.746 & & \\
\hline \multicolumn{7}{|c|}{ Contrasts of VHN for enamel } \\
\hline Source & Stage & SS & $d f$ & MS & $\boldsymbol{F}$ & $p$-value \\
\hline \multirow[t]{2}{*}{ Stage } & $B_{D}$ vs $A_{D}$ & $\mathrm{I}, 4 \mid 4,780.027$ & 1 & $\mathrm{I}, 4 \mid 4,780.027$ & $3,076.973$ & 0.000 \\
\hline & $A_{D}$ vs $A_{R}$ & $16,483.477$ & I & $16,483.477$ & 404.492 & 0.000 \\
\hline \multirow[t]{2}{*}{ Stage $\times$ material } & $B_{D}$ vs $A_{D}$ & 51.790 & 2 & 25.895 & 0.056 & 0.945 \\
\hline & $A_{D}$ vs $A_{R}$ & $8,752.192$ & 2 & $4,376.096$ & 107.386 & 0.000 \\
\hline \multirow[t]{2}{*}{ Error } & $B_{D}$ vs $A_{D}$ & $|2,4| 4.495$ & 27 & 459.796 & & \\
\hline & $A_{D}$ vs $A_{R}$ & $\mathrm{I}, 100.280$ & 27 & 40.751 & & \\
\hline \multicolumn{7}{|c|}{ ANOVA of VHN for cementum } \\
\hline \multicolumn{2}{|l|}{ Source } & SS & $d f$ & MS & $\boldsymbol{F}$ & $p$-value \\
\hline \multicolumn{2}{|l|}{ Intercept } & $35,698.531$ & 1 & $35,698.531$ & $10,623.760$ & 0.000 \\
\hline \multicolumn{2}{|l|}{ Material } & 121.535 & 2 & 60.767 & 18.084 & 0.000 \\
\hline \multicolumn{2}{|l|}{ Error } & 90.727 & 27 & 3.360 & & \\
\hline \multicolumn{7}{|c|}{ Contrasts of VHN for cementum } \\
\hline Source & Stage & SS & $d f$ & MS & $\boldsymbol{F}$ & $p$-value \\
\hline \multirow[t]{2}{*}{ Stage } & $B_{D}$ vs $A_{D}$ & $56,952.090$ & 1 & $56,952.090$ & $4,038.439$ & 0.000 \\
\hline & $A_{D}$ vs $A_{R}$ & 689.569 & 1 & 689.569 & 186.233 & 0.000 \\
\hline \multirow[t]{2}{*}{ Stage $\times$ material } & $B_{D}$ vs $A_{D}$ & 11.765 & 2 & 5.882 & 0.417 & 0.663 \\
\hline & $A_{D}$ vs $A_{R}$ & 527.414 & 2 & 263.707 & 71.220 & 0.000 \\
\hline \multirow[t]{2}{*}{ Error } & $B_{D}$ vs $A_{D}$ & 380.768 & 27 & 14.103 & & \\
\hline & $A_{D}$ vs $A_{R}$ & 99.973 & 27 & 3.703 & & \\
\hline
\end{tabular}

Abbreviations: $A_{D}$, after demineralization; $A_{R}$, after remineralization; $A N O V A$, analysis of variance; $B_{D}$, before demineralization; $d f$, degree of freedom; $F, F$-ratio; $M S$, mean square; SS, sum of squares; VHN, Vickers microhardness.

of the weight in CP may face more difficulty in undergoing a crystallization to promote surface remineralization. The calcium, phosphate, and fluoride composition in CP is capable of only replacing the lost mineral, by forming fluoroapatite crystal in the remineralization process. ${ }^{22}$

Table 3 Multiple comparisons of VHN of enamel and cementum upon application of NHA and $\mathrm{CP}$ in comparison with NT at different stages including $B_{D}, A_{D}$, and $A_{R}$

\begin{tabular}{|l|l|l|l|l|l|l|l|l|}
\hline Stage & \multicolumn{3}{l}{ Enamel } & \multicolumn{4}{l|}{ Cementum } \\
\hline$A_{D}-B_{D}$ & & NT & NHA & CP & & NT & NHA & CP \\
\cline { 2 - 9 } & NT & 1.000 & 1.000 & 1.000 & NT & 1.000 & 1.000 & 1.000 \\
\cline { 2 - 9 } & NHA & & 1.000 & 1.000 & NHA & & 1.000 & 1.000 \\
\cline { 2 - 10 } & CP & & & 1.000 & CP & & & 1.000 \\
\hline \multirow{3}{*}{$A_{R}-A_{D}$} & & NT & NHA & CP & & NT & NHA & CP \\
\cline { 2 - 10 } & NT & 1.000 & 0.000 & 0.000 & NT & 1.000 & 0.000 & 0.000 \\
\cline { 2 - 9 } & NHA & & 1.000 & 0.025 & NHA & & 1.000 & 0.000 \\
\cline { 2 - 9 } & CP & & & 1.000 & CP & & & 1.000 \\
\hline
\end{tabular}

Abbreviations: $A_{D}$, after demineralization; $A_{R}$, after remineralization; $B_{D}$, before demineralization; CP, Clinpro; NHA, nano-hydroxyapatite; NT, no treatment; VHN, Vickers microhardness.
The demineralized enamel surface was considerably rough and slightly porous. ${ }^{12}$ This facilitated the NHA to penetrate into the interprismatic spaces because of the precipitation process. Additionally, it also attracted a large amount of $\mathrm{Ca}^{2+}$ and $\left(\mathrm{PO}_{4}\right)^{3-}$ from the saturated solution at the outer layer of enamel surface to refill the vacant positions of the crystals. $^{23,25}$ The demineralization of cementum clearly showed the surface's exposed tubules. Numerous mineral deposits were found in the tubules, which also might have contributed to the remineralization effect. ${ }^{10,11}$ The remineralization of cementum upon using NHA and CP is possibly associated with the exchange of minerals between the cementum surface and the surrounding environment, as is found in the enamel. However, the remineralization process in cementum is less effective than in enamel, as supported by the XRD, which indicated an increase in the peak intensities possibly related to the lack of protein scaffold in cementum to promote the remineralization process. ${ }^{23,33}$ However, the higher capability of remineralization in cementum for NHA as compared to $\mathrm{CP}$ is possibly associated with the nanoparticle size that is 

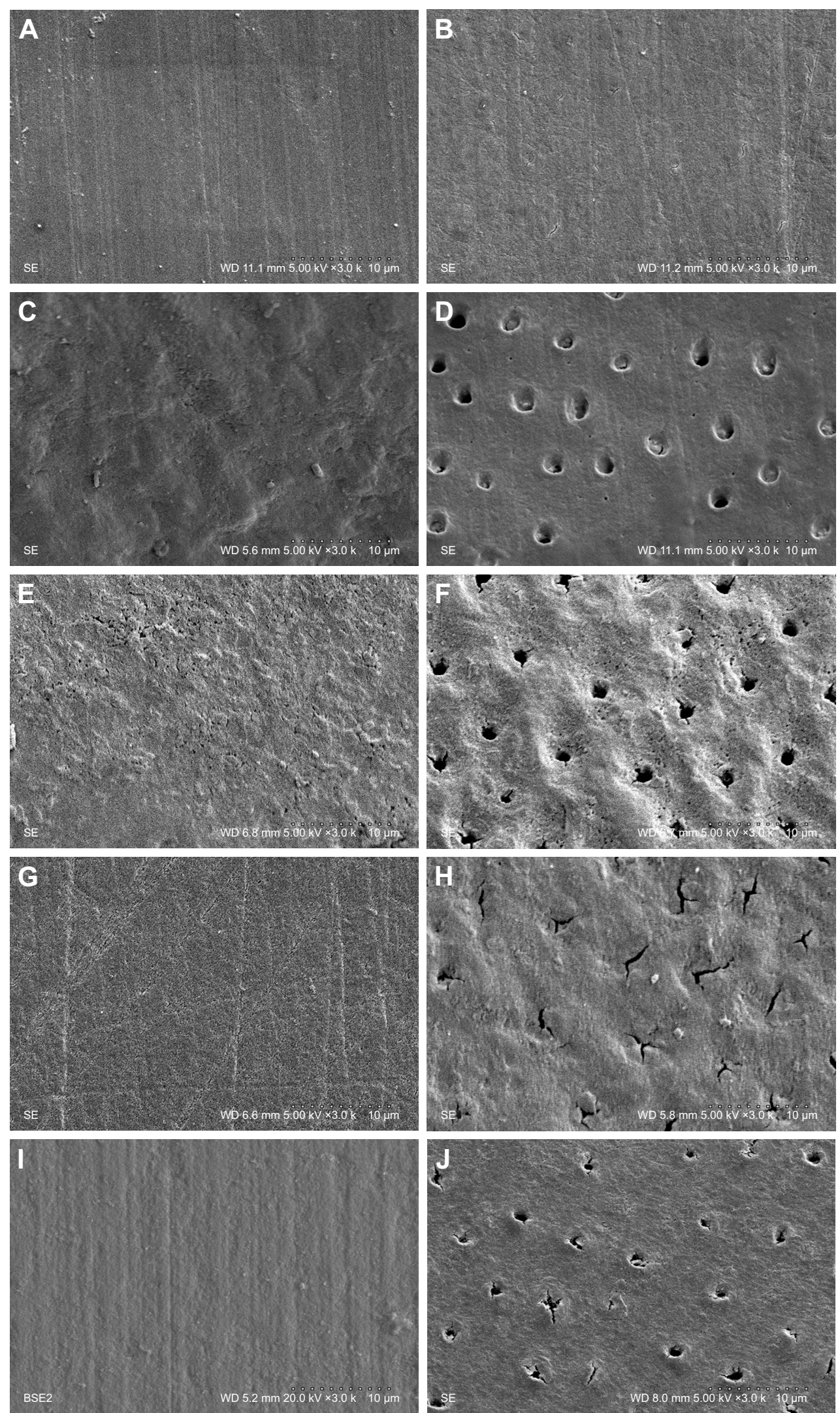

Figure 4 SEM of enamel $(\mathbf{A}, \mathbf{C}, \mathbf{E}, \mathbf{G}$, and $\mathbf{I})$ and cementum (B, D, F, H, and $\mathbf{J})$ surface $\mathrm{B}_{\mathrm{D}}(\mathbf{A}$ and $\mathbf{B}), \mathrm{A}_{\mathrm{D}}(\mathbf{C}$ and $\mathbf{D})$, with no treatment application $(\mathbf{E}$ and $\mathbf{F})$, after application of $\mathrm{NHA}(\mathbf{G}$ and $\mathbf{H})$ and $\mathrm{CT}$ (I and $\mathbf{J})$.

Abbreviations: $A_{D}$, after demineralization; $B_{D}$, before demineralization; CP, Clinpro; NHA, nano-hydoxyapatite; SEM, scanning electron microscopy. 
capable of constructive interdigitation upon the cementum structure. ${ }^{32}$ Deionized water was used in this experiment as an alternative to artificial saliva to eliminate the confounding factors that could occur as a result of other components such as amino acids in salivary protein that possibly affect the natural enamel matrix proteins of tooth specimens. ${ }^{14}$ In addition, minerals in artificial saliva may affect the confounding factors during remineralization process, as the deproteination of enamel results in a significant reduction of enamel resistance and characteristics. ${ }^{30,32}$ However, this study indicated that NHA has strong surface remineralization capability for the enamel and cementum surrounding the ceramic restoration. The novel NHA gel has a promising remineralization potential for the enamel and cementum surrounding margin of the restoration. Ultimately, although clinicians provide the best ceramic restoration to the patient, marginal discrepancy in the restoration to the tooth abutment still exists, which is a challenging circumstance for the product like NHA gel to combat secondary caries surrounding the margin of the restoration through the remineralization process. The finding indicates the capacity of NHA as a promising early therapeutic aspect in restorative dentistry, and should be introduced as an initial therapeutic aspect of caries management surrounding margin of the restoration in contemporary fixed prosthodontic reconstruction. A further clinical study is needed to determine the efficacy of using NHA gel in daily clinical practice.

\section{Conclusion}

The application of NHA to combat dental caries through the remineralization process is a relatively new approach in restorative dentistry. In the view of recurrent caries at the tooth-restoration margin as the main factor for restoration failure, NHA and CP showed significant capability in remineralization of the enamel and cementum surrounding

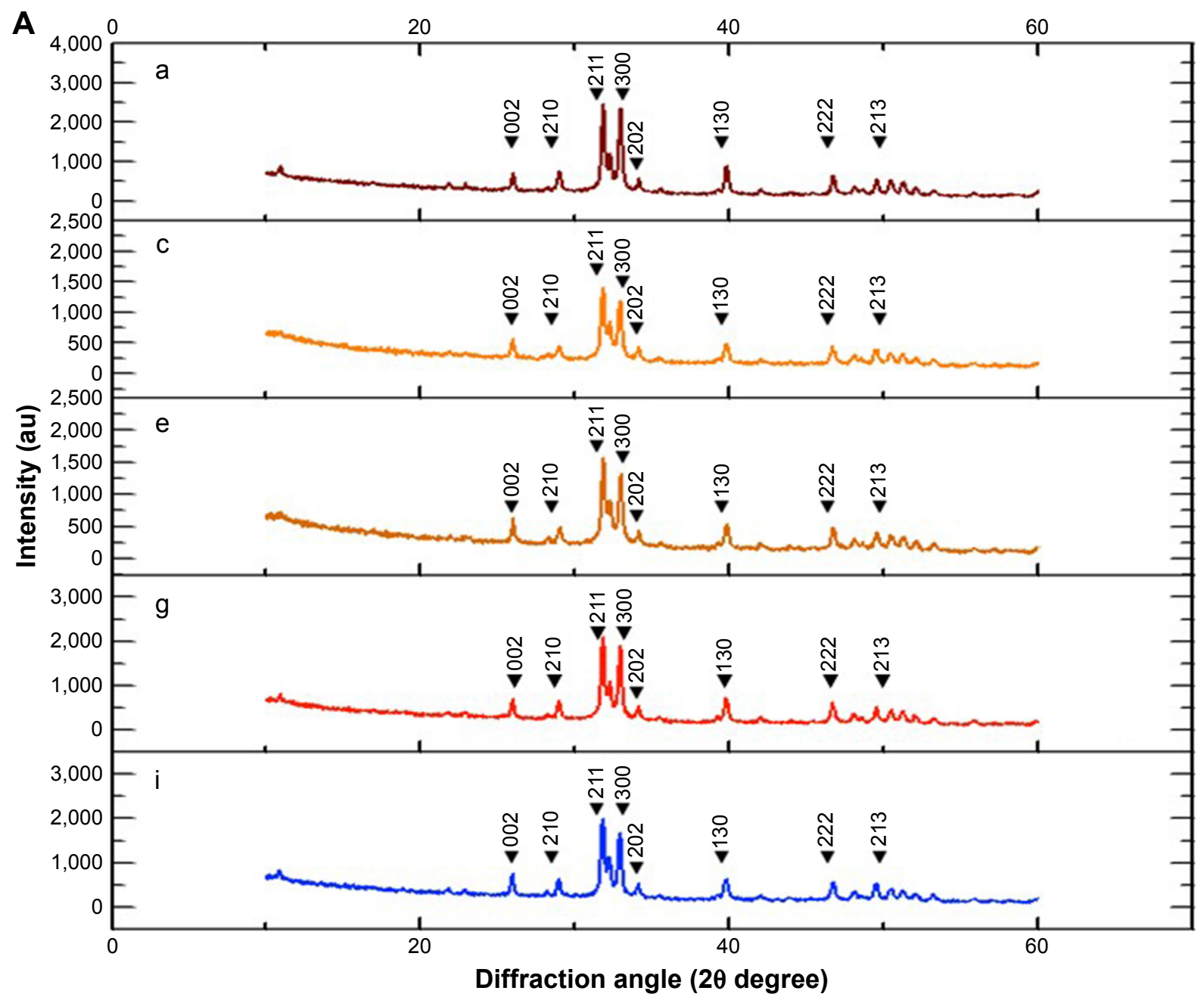

Figure 5 (Continued) 


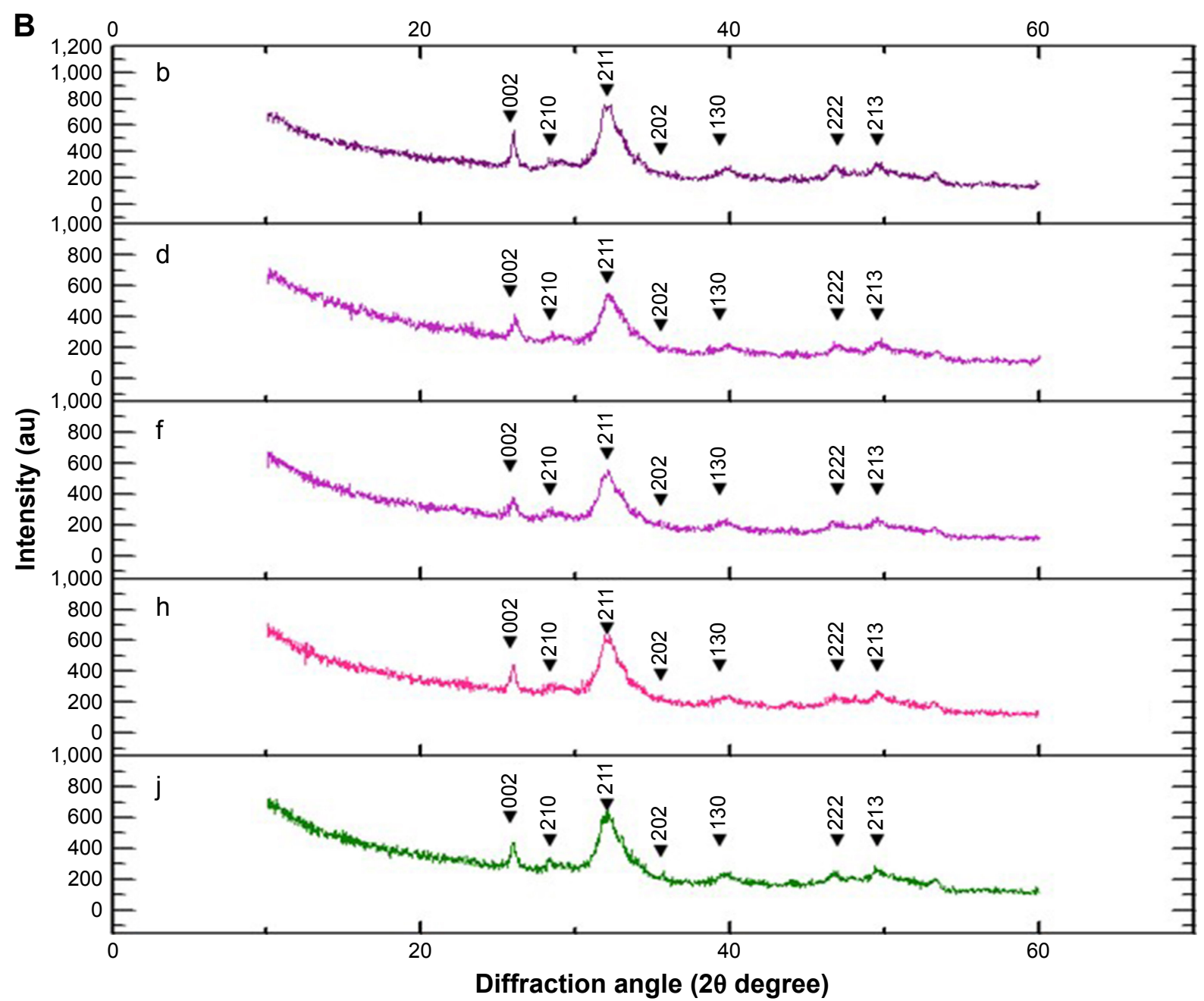

Figure 5 The XRD pattern of enamel $(\mathbf{A})$ and cementum $(\mathbf{B}) B_{D}(a$ and $b), A_{D}$ (c and d), no treatment application (e and f), and after application of $\mathrm{NHA}$ ( $g$ and $h$ ) and $C P$ (i and j).

Abbreviations: $A_{D}$, after demineralization; $B_{D}$, before demineralization; $C P$, Clinpro; NHA, nano-hydroxyapatite; $X R D, X$-ray diffraction.

the finishing area of CAD-CAM restoration, which resulted in effective caries inhibition. NHA exhibited better remineralization than $\mathrm{CP}$, and hence is better for use in the remineralization process both in the enamel and cementum. The NHA gel indicated a new paradigm for initial caries therapeutic aspect surrounding the margin of restoration to provide long-term success of the treatment.

\section{Clinical significance}

NHA gel has significant potential in the remineralization process for enamel and cementum surrounding the margin of restoration and is recommended for use in restorative reconstruction.

\section{Disclosure}

The authors report no conflicts of interest in this work.

\section{References}

1. Denry I, Kelly JR. Emerging ceramic-based materials for dentistry. $J$ Dent Res. 2014;93(12):1235-1242.

2. Felton DA, Kanoy BE, Bayne SC, Wirthman GP. Effect of in vivo crown margin discrepancies on periodontal health. J Prosthet Dent. 1991; 65(3):357-364.

3. Bohaty BS, Ye Q, Misra A, Sene F, Spencer P. Posterior composite restoration update: focus on factors influencing form and function. Clin Cosmet Investig Dent. 2013;5:33-42.

4. Featherstone JD. The continuum of dental caries - evidence for a dynamic disease process. J Dent Res. 2004;83(Spec No C):C39-C42.

5. Cheng L, Zhang K, Weir MD, Melo MA, Zhou X, Xu HH. Nanotechnology strategies for antibacterial and remineralizing composites and adhesives to tackle dental caries. Nanomedicine (Lond). 2015;10(4):627-641.

6. Mjor IA. Clinical diagnosis of recurrent caries. J Am Dent Assoc. 2005; 136(10):1426-1433.

7. Goodacre CJ, Bernal G, Rungcharassaeng K, Kan JY. Clinical complications in fixed prosthodontics. J Prosthet Dent. 2003;90(1):31-41.

8. Gordan VV, Garvan CW, Heft MW, et al; DPBRN Collaborative Group. Restorative treatment thresholds for interproximal primary caries based on radiographic images: findings from The Dental Practice-Based Research Network. Gen Dent. 2009;57(6):654-663. 
9. Zoellner A, Diemer B, Weber HP, Stassinakis A, Gaengler P. Histologic and radiographic assessment of caries-like lesions localized at the crown margin. J Prosthet Dent. 2002;88(1):54-59.

10. Schüpbach P, Lutz F, Guggenheim B. Human root caries: histopathology of arrested lesions. Caries Res. 1992;26(3):153-164.

11. González-Cabezas C. The chemistry of caries: remineralization and demineralization events with direct clinical relevance. Dent Clin North Am. 2010;54(3):469-478.

12. Klarić E, Marcius M, Ristić M, Sever I, Prskalo K, Tarle Z. Surface changes of enamel and dentin after two different bleaching procedures. Acta Clin Croat. 2013;52(4):419-429.

13. Malekafzali B, Ekrami M, Mirfasihi A, Abdolazimi Z. Remineralizing effect of child formula dentifrices on artificial enamel caries using a pH cycling model. J Dent (Tehran). 2015;12(1):11-17.

14. Vyavhare S, Sharma DS, Kulkarni VK. Effect of three different pastes on remineralization of initial enamel lesion: an in vitro study. J Clin Pediatr Dent. 2015;39(2):149-160.

15. Kalra DD, Kalra RD, Kini PV, Prabhu CA. Nonfluoride remineralization: An evidence-based review of contemporary technologies. J Dent Allied Sci. 2014;3(1):24-33.

16. Khajuria DK, Vasireddi R, Trebbin M, Karasik D, Razdan R. Novel therapeutic intervention for osteoporosis prepared with strontium hydroxyapatite and zoledronic acid: in vitro and pharmacodynamic evaluation. Mater Sci Eng C Mater Biol Appl. 2017;71:698-708.

17. Sahana H, Khajuria DK, Razdan R, et al. Improvement in bone properties by using risedronate adsorbed hydroxyapatite novel nanoparticle based formulation in a rat model of osteoporosis. J Biomed Nanotechnol. 2013;9(2):193-201.

18. Khajuria DK, Zahra SF, Razdan R. Effect of locally administered novel biodegradable chitosan based risedronate/zinc-hydroxyapatite intrapocket dental film on alveolar bone density in rat model of periodontitis. J Biomater Sci Polym Ed. 2018;29(1):74-91.

19. Hannig M, Hannig C. Nanotechnology and its role in caries therapy. Adv Dent Res. 2012;24(2):53-57.

20. Allaker RP, Ren G. Potential impact of nanotechnology on the control of infectious diseases. Trans R Soc Trop Med Hyg. 2008;102(1):1-2.

21. Naik NS, Subba Reddy VV, Shashikiran ND. Comparative evaluation of secondary caries formation around light-cured fluoride-releasing restorative materials. J Indian Soc Pedod Prev Dent. 2017;35(1):75-82.
22. Oliveby A, Twetman S, Ekstrand J. Diurnal fluoride concentration in whole saliva in children living in a high- and a low-fluoride area. Caries Res. 1990;24(1):44-47.

23. Hannig M, Hannig C. Nanomaterials in preventive dentistry. Nat Nanotechnol. 2010;5(8):565-569.

24. Goldberg M, Kulkarni AB, Young M, Boskey A. Dentin: structure, composition and mineralization. Front Biosci (Elite Ed). 2011;3:711-735.

25. Huang SB, Gao SS, Yu HY. Effect of nano-hydroxyapatite concentration on remineralization of initial enamel lesion in vitro. Biomed Mater. 2009;4(3):034104.

26. Pepla E, Besharat LK, Palaia G, Tenore G, Migliau G. Nanohydroxyapatite and its applications in preventive, restorative and regenerative dentistry: a review of literature. Ann Stomatol (Roman). 2014; 5(3):108-114

27. Tschoppe P, Zandim DL, Martus P, Kielbassa AM. Enamel and dentine remineralization by nano-hydroxyapatite toothpastes. J Dent. 2011;39(6):430-437.

28. Huang S, Gao S, Cheng L, Yu H. Combined effects of nano-hydroxyapatite and Galla chinensis on remineralisation of initial enamel lesion in vitro. $J$ Dent. 2010;38(10):811-819.

29. Kunin AA, Evdokimova AY, Moiseeva NS. Age-related differences of tooth enamel morphochemistry in health and dental caries. EPMAJ 2015;6(1):3

30. Lubarsky GV, Lemoine P, Meenan BJ, et al. Enamel proteins mitigate mechanical and structural degradations in mature human enamel during acid attack. Mater Res Express. 2014;1(2):025404.

31. Wang H, Xiao Z, Yang J, et al. Oriented and ordered biomimetic remineralization of the surface of demineralized dental enamel using HAP@ACP nanoparticles guided by glycine. Sci Rep. 2017;7:40701.

32. Ruan Q, Moradian-Oldak J. Amelogenin and enamel biomimetics. J Mater Chem B. 2015;3(16):3112-3129.

33. Reyes-Gasga J, Koudriavtseva O, Herrera-Becerra R, Escobosa A. XRD characterization of crystallinity of human tooth enamel under influence of mechanical grinding. Mater Sci Appl. 2015;6(6):464-472.

34. Reynolds E. Remineralization of enamel subsurface lesions by casein phosphopeptide-stabilized calcium phosphate solutions. J Dent Res. 1997;76(9):1587-1595.
International Journal of Nanomedicine

\section{Publish your work in this journal}

The International Journal of Nanomedicine is an international, peerreviewed journal focusing on the application of nanotechnology in diagnostics, therapeutics, and drug delivery systems throughout the biomedical field. This journal is indexed on PubMed Central, MedLine, CAS, SciSearch $®$, Current Contents $\AA /$ Clinical Medicine,

\section{Dovepress}

Journal Citation Reports/Science Edition, EMBase, Scopus and the Elsevier Bibliographic databases. The manuscript management system is completely online and includes a very quick and fair peer-review system, which is all easy to use. Visit http://www.dovepress.com/ testimonials.php to read real quotes from published authors. 